\title{
Neurodegenerative Disorders Increase Decline in Respiratory Muscle Strength in Older Adults
}

\author{
Vinicius S Sanches PT, Fabiana M Santos PT, Janainny M Fernandes PT, \\ Mara LM Santos PhD, Paulo T Müller PhD, and Gustavo Christofoletti PhD
}

\begin{abstract}
INTRODUCTION: Respiratory muscle strength (RMS) is a determinant of vital capacity, and its decline can lead to inadequate ventilation and deficiency in the elimination of secretions from the airways. Studies analyzing RMS in older adults with Parkinson's disease (PD) and Alzheimer's disease (AD) remain scarce, making the analysis of this variable still very uncertain. The aim of this study was to analyze the RMS of older adults diagnosed with PD and AD, in relation to healthy control peers. METHODS: A cross-sectional study was conducted involving 65 older adults comprising 3 groups: PD $(n=20), \mathrm{AD}(n=20)$, and control $(n=25)$. The participants underwent anthropometric and cirtometric measurements associated with maximal respiratory pressures. We analyzed data using descriptive (mean and SD) and inferential statistics (1-way analysis of variance, Student $t$ test, and Scheffé post hoc) with a level of significance of $5 \%(P<.05)$ and a CI of 95\%. RESULTS: Although the anthropometric and cirtometric variables indicated similarity of values between groups $(P>.05)$, the maximal inspiratory and expiratory pressures were considerably lower in the subjects with $\mathrm{PD}$ and $\mathrm{AD}(P<.01)$. CONCLUSIONS: The control of the anthropometric and cirtometric variables of the subjects indicates that RMS is affected by the aging process, and its decline increases in neurodegenerative conditions. This fact represents a serious risk for the development of atelectasis and other pneumo-functional complications, which must be considered in proposing of future therapies. Key words: Parkinson's disease; Alzheimer's disease; airway pressure; respiratory function tests; public health; critical care. [Respir Care 2014;59(12):1838-1845. @ 2014 Daedalus Enterprises]
\end{abstract}

\section{Introduction}

Respiratory dysfunctions represent serious problems for the population's health and are related to growing rates of

\footnotetext{
The authors are affiliated with the Biological and Health Sciences Centre, Federal University of Mato Grosso do Sul, Campo Grande, Mato Grosso do Sul, Brazil.

Dr Christofoletti presented a version of this paper at the 11th International Conference on Alzheimer's and Parkinson's Diseases, held March 6-10, 2013, in Florence, Italy.

The authors have disclosed no conflicts of interest.

Correspondence: Gustavo Christofoletti PhD, Federal University of Mato Grosso do Sul, Biological and Health Science Center, Curso de Fisioterapia, Avenida Universitária, s/n, Setor Universitário, Caixa postal 549, 79060-900 Campo Grande, Mato Grosso do Sul, Brazil. E-mail: g.christofoletti@ufms.br.
}

DOI: $10.4187 /$ respcare. 03063 co-morbidities and deaths. With the physiological process of aging, lung function undergoes changes in capacity, volume, and respiratory flow, caused by the loss of elasticity of pulmonary tissue, alveolar dilatation, and drops in the neural transmission and stimuli in the respiratory muscles. ${ }^{1,2}$ Respiratory muscle strength (RMS) is a determinant of the subjects' vital capacity, and its decline can lead to inadequate ventilation, particularly when linked with chronic neuromuscular conditions. , $^{3,4}$

Lower pulmonary function has been correlated with poor cognitive performance in patient populations as well as in community-dwelling subjects with a wide range of health statuses and ethnicities. ${ }^{5}$ However, studies evaluating RMS in neurodegenerative illnesses, such as Parkinson's disease (PD) and Alzheimer's disease (AD), remain scarce and with little scientific evidence. ${ }^{6}$

Regarding PD, it is important to emphasize that it is a progressive disorder characterized by the presentation of clinical signs of bradykinesia, rigidity, tremor at rest, and impairment of postural reflexes. ${ }^{7}$ In addition to this, the 
illness can lead to obstruction of the upper airways, restrictive defects, and inadequate ventilatory control. ${ }^{8}$

On the other hand, $\mathrm{AD}$ is characterized as one of the most prevalent causes of dementia in the world. It originally affects the basal nucleus of Meynert and is defined post mortem by the presence of amyloid plaques and neurofibrillary tangles. ${ }^{9}$ Its relation to dysfunctions of the respiratory tract can be linked with the subject's physical decline, arising, above all, from the depletion in the levels of acetylcholine and changes in the N-methyl-D-aspartate receptors in the brain. ${ }^{10,11}$

Although these conditions present psychological-behavioral and neuromotor impairments as the principal dysfunctions, one must also consider the influence of the brain alterations in RMS. Hence, it is necessary to evaluate the subjects' pulmonary function so as to ascertain the need to establish a guided and efficacious therapeutic plan for patients with such conditions.

This study aimed to analyze the maximum RMS (inspiratory and expiratory) of older adults diagnosed with $\mathrm{PD}$ and $\mathrm{AD}$ in relation to healthy control peers.

\section{Methods}

In this cross-sectional study design, 65 males and females (60-80 y of age at entry) were recruited into three groups: PD (20 older adults diagnosed with $\mathrm{PD}, 12$ who were in stages 2, 3, or 4 of the Hoehn-Yahr scale $\left.{ }^{13}\right)$, AD (20 older adults with $\mathrm{AD},{ }^{14}$ who were in the moderate stage on the Clinical Dementia Rating ${ }^{15}$ ), and control group (CG, made up of 25 older adults). We allowed for a $5 \%$ margin of error, an effect size of 0.40 , and a statistical power of $80 \%$ to calculate the necessary sample size. Based on this calculation, the sample size should be 65 subjects.

This study was performed at the Neurologic Outpatient Clinic of University Hospital (Campo Grande, Mato Grosso do Sul, Brazil), and all patients enrolled in the study were selected from this clinic. Ethical approval was obtained from the local research ethics committee (protocol 31,834), and this study complied with the Helsinki Declaration. Informed consent forms were signed by all subjects participating in this study. For AD subjects, the patient's next of kin (usually the main family caregiver) was approached to give informed consent.

With respect to the inclusion criteria, subjects were admitted with the clinical conditions described, ${ }^{12,14}$ all sedentary (not performing any physical activity superior to 3 metabolic equivalents of task), and independent for orthostatism and locomotion. A history of tobacco use, previous respiratory conditions (such as COPD, asthma, bronchitis, pneumonia, tuberculosis, sarcoidosis, or neoplasias), thoracic alterations (barrel chest, pigeon chest, excavatum, carinatum, or kyphoscoliotic) and serious cognitive decline, evidenced by a score $<5.0$ on the mini-mental state

\section{QUICK LOOK}

\section{Current knowledge}

Respiratory muscle strength is a determinant of vital capacity, and its decline can lead to inadequate ventilation and secretion retention. Neurologic and neuromuscular diseases and increasing age conspire to reduce respiratory muscle strength.

\section{What this paper contributes to our knowledge}

Respiratory muscle strength is affected by the aging process, and its decline increases in neurodegenerative conditions, including Alzheimer's and Parkinson's disease.

examination ${ }^{16}$ (which would make it impossible for the participants to understand the tasks adequately) were stipulated as exclusion criteria. Cases involving dementia in PD and mixed dementias (Alzheimer's plus vascular) were also excluded.

Subjects were selected by referral from a doctor (neurologist or psychiatrist), with the predefined clinical diagnosis. Control subjects were selected during the same time period of case recruitment. The control group was essentially a convenience sample, selected to match the profile of the subjects with $\mathrm{AD}$ and PD.

No subject had renal or cardiac dysfunctions. Those with diabetes mellitus type 2 and hypertension were controlled under normal parameters. Furthermore, none of the participants had been hospitalized in the last 6 months or received any respiratory physical therapy.

\section{Evaluative Procedures}

The evaluative procedures involved the measuring of the thoracic cirtometry $(\mathrm{cm})$, standardized in the subject's right and left armpits. For the analysis of the participants' RMS, a previously-calibrated manometer, graduated in $\mathrm{cm}$ $\mathrm{H}_{2} \mathrm{O}$ was used.

The cirtometry consisted of measuring the chest circumference with a measuring tape. The standardized procedure was to keep the 0 point of the tape fixed on the midline of the body, horizontally aligned with the landmarks, while the other end of the tape was allowed to move. The tape was snug but not tight, so that the soft-tissue contours remained unchanged. For this measurement, the subjects were asked to perform maximum inspiration and expirations twice, and to hold the maximum inspiration or expiration for at least $2 \mathrm{~s}$, during which the measurements were taken. ${ }^{17}$ Through this procedure, it was possible to analyze the thoracic mobility in the situations of normal 


\section{Respiratory Strength in Parkinson's and Alzheimer's Disease}

respiration and sustained maximum inspiration and expiration.

Maximum inspiratory pressure $\left(\mathrm{P}_{\text {Imax }}\right)$, followed by maximum expiratory pressure $\left(\mathrm{P}_{\text {Emax }}\right)$, was obtained starting at residual volume or total lung capacity, respectively, with the subject seated (maintaining $90^{\circ}$ of flexion in their knees and hips), wearing a nose clip, and with a rigid, plastic, flanged mouthpiece. A small leak was introduced between the occlusion and the mouth to prevent glottic closure, and the subject held his or her cheeks with one hand during the maneuver. Due to the evaluative standards previously accepted in the literature, ${ }^{18}$ this maneuver was undertaken 5 times, with a minimum of 3 correct measurements being accepted, technically characterized as: (1) absence of air leaks in the procedure, (2) minimum duration of $3 \mathrm{~s}$, (3) a gross value that did not exceed the other accepted values by $10.0 \%$, and (4) the last value not being higher than the others (which would entail the undertaking of a new respiratory maneuver).

Before the test, we assessed the ability of subjects to demonstrate proper task performance. Subjects with PD and $\mathrm{AD}$ were tested while on their medications: the PD subjects using drugs for which the active ingredient was based on dopamine, and the AD subjects using drugs for which the active ingredients were based on inhibitors of the acetylcholinesterase enzyme and N-methyl-D-aspartate receptor antagonists.

\section{Statistical Analysis}

We analyzed data using descriptive statistics (mean, SD, and percentage analysis) to characterize the sample, and inferential statistics to compare the values obtained between groups.

We complied with the precepts of normality and homogeneity required by the parametric statistics. Thus, the cross-sectional analysis obeyed the following system: if the variable presented a continuous character, 1-way analysis of variance was applied. The Scheffé post hoc test was applied for comparing the results between the groups, and the Student $t$ test for independent samples was applied for comparing values between men and women from each group.

If the variable had a nominal categorical character, the nonparametric chi-square test was applied. A level of significance of $5 \%(P<.05)$ with a CI of $95 \%$ was considered in all the analyses.

\section{Results}

Sixty-five older adults participated in this study, of whom 29 were men $(44.6 \%)$ and 36 were women $(55.4 \%)$. The subjects' mean age was $72.26 \pm 7.93 \mathrm{y}$ old, and all were resident in the city of Campo Grande, in the state of Mato
Table 1. Subject Characteristics

\begin{tabular}{lcccl}
\hline \hline & $\begin{array}{c}\text { Parkinson's } \\
\text { Group }\end{array}$ & $\begin{array}{c}\text { Alzheimer's } \\
\text { Group }\end{array}$ & $\begin{array}{c}\text { Control } \\
\text { Group }\end{array}$ & $P$ \\
\hline Sample size $(n)$ & 20 & 20 & 25 & .68 \\
Gender (M:F) & $11: 9$ & $8: 12$ & $10: 15$ & .78 \\
Age (y) & $71.0 \pm 7.72$ & $77.1 \pm 5.50$ & $69.4 \pm 8.21$ & .003 \\
Height (m) & $1.60 \pm 0.09$ & $1.58 \pm 0.08$ & $1.62 \pm 0.07$ & .38 \\
Weight (kg) & $70.8 \pm 9.74$ & $66.0 \pm 11.0$ & $72.4 \pm 17.3$ & .27 \\
BMI & $27.6 \pm 3.38$ & $26.1 \pm 3.22$ & $27.4 \pm 5.68$ & .48 \\
MMSE & $25.2 \pm 4.61$ & $18.0 \pm 6.71$ & $24.7 \pm 4.42$ & .001 \\
& & & & \\
M $=$ male & & & & \\
F= female & & & & \\
BMI = body mass index & & & & \\
MMSE = mini-mental state examination & & & \\
&
\end{tabular}

Grosso do Sul, Brazil. Table 1 shows the groups' characteristics in relation to gender, age, weight, height, body mass index, and cognitive functions.

As may be observed in Table 1, the groups analyzed were homogeneous regarding sample size $(P=.68)$, gender $(P=.78)$, height $(P=.38)$, weight $(P=.27)$, and body mass index $(P=.48)$. In relation to the participants' ages, differences were found between the groups $(P=.01)$, being evidenced in the comparisons between the Parkinson's and Alzheimer's groups $(P=.03,95 \% \mathrm{CI}=-11.95$ to -0.34$)$ and between the Alzheimer's and control groups $(P=.01,95 \% \mathrm{CI}=0.34$ to 11.95$)$. Regarding the $\operatorname{cog}$ nitive score evaluated in the mini-mental state examination, there was a significant difference between the groups $(P=.01)$, particularly in the comparisons between the Alzheimer's and Parkinson's groups $(P=.01,95 \% \mathrm{CI}$ $=-11.56$ to -2.81$)$ and the Alzheimer's and control groups $(P=.01,95 \% \mathrm{CI}=-11.03$ to -2.37$)$.

\section{$\mathbf{P}_{\text {Imax }}$ and $\mathbf{P}_{\text {Emax }}$ Values}

Figure 1 details the $\mathrm{P}_{\text {Imax }}$ and $\mathrm{P}_{\text {Emax }}$ values. The statistical analysis indicated differences between the groups both for inspiratory strength values $(P=.01)$ and for maximum expiratory values $(P=.01)$. Although different values were found for $\mathrm{P}_{\text {Imax }}$ and $\mathrm{P}_{\mathrm{Emax}}$, no participant presented with dyspnea or other respiratory complaints during the evaluation.

Regarding pairwise comparisons, a significant difference of $\mathrm{P}_{\text {Imax }}$ was observed between the Alzheimer's and control groups $(P=.01,95 \% \mathrm{CI}=-46.30$ to -11.85$)$ and a tendency of significance between the Parkinson's and control groups $(P=.06,95 \% \mathrm{CI}=-37.1$ to .58$)$. In relation to the $\mathrm{P}_{\text {Emax }}$, the comparison evidenced a difference between the Parkinson's and control groups $(P=.01$, 95\% CI $=-46.01$ to -11.55$)$, and between the Alzheimer's and control groups $(P=.01,95 \% \mathrm{CI}=-46.31$ to -11.85$)$. 


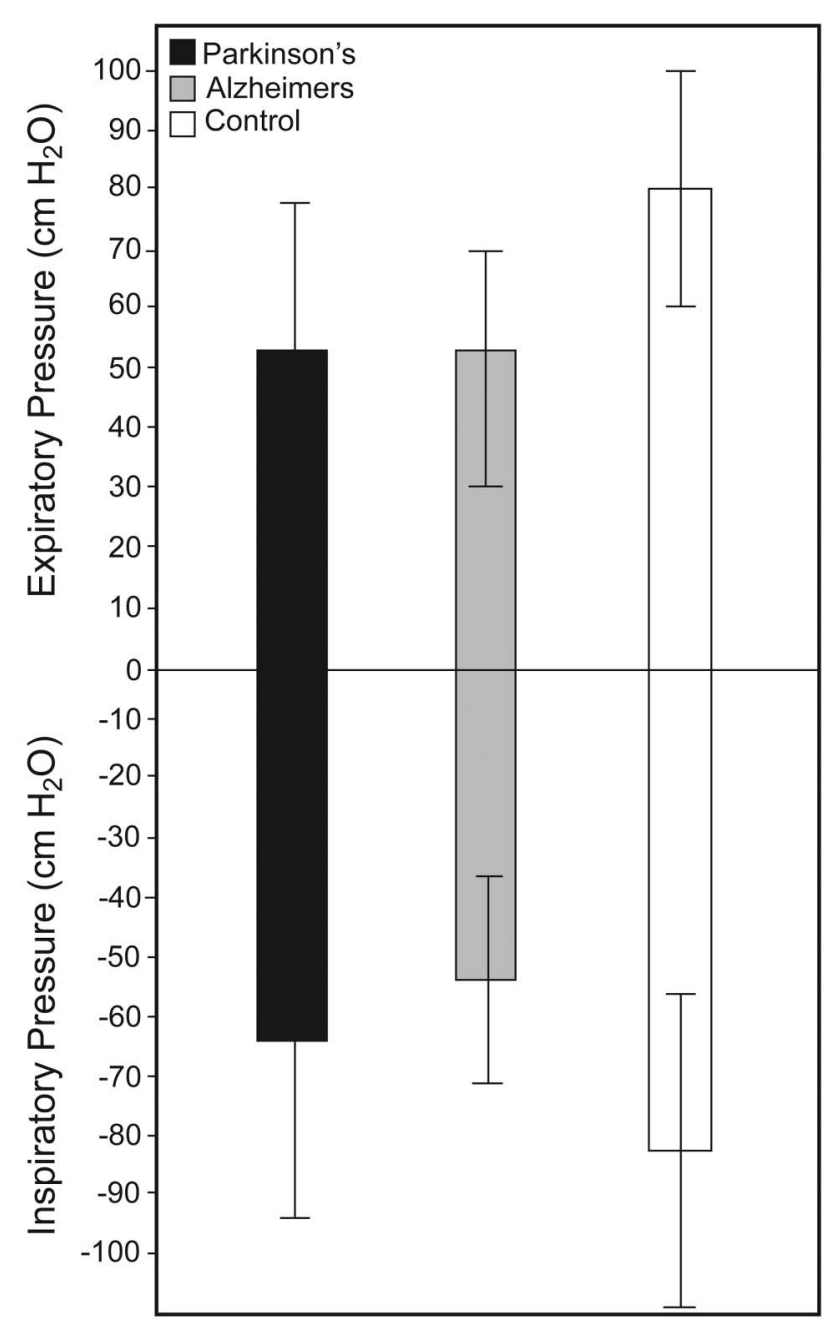

Fig. 1. Maximum inspiratory and expiratory values for each group. Data are shown as mean \pm SD.

\section{$\mathbf{P}_{\text {Imax }}$ and $\mathbf{P}_{\text {Emax }}$ by Gender}

Table 2 shows the $\mathrm{P}_{\text {Imax }}$ and $\mathrm{P}_{\text {Emax }}$ values of the groups by the participants' gender, compared against the mean ages of the same and the staging of PD and AD in the respective groups.

Through the Student $t$ test for independent samples, we observed that there was no significant difference between the mean ages for men and women in the Parkinson's group $(P=.63,95 \% \mathrm{CI}=-5.71$ to 9.16$)$, Alzheimer's group $(P=.73,95 \% \mathrm{CI}=-4.53$ to 6.28$)$, and control group $(P=.86,95 \% \mathrm{CI}=-6.47$ to 7.67$)$. In relation to the extent of the progression of the participants' illnesses, there was no difference between the staging in comparisons between men and women from the Parkinson's $(P=.96,95 \% \mathrm{CI}=-0.48$ to 0.50$)$ and Alzheimer's group $(P=.60,95 \% \mathrm{CI}=-0.37$ to 0.62$)$, indicating statistical similarity.
Regarding the values referent to the $\mathrm{P}_{\text {Imax }}$, we observed a significant difference between the sexes only in the Parkinson's group ( $P=.02,95 \% \mathrm{CI}=3.57$ to 51.27$)$. In relation to the $\mathrm{P}_{\text {Emax }}$ values, we observed a significant gender difference in the Parkinson's group $(P=.02$, $95 \% \mathrm{CI}=3.50$ to 50.43$)$ and in the Alzheimer's group $(P=.04,95 \% \mathrm{CI}=0.93$ to 35.48$)$.

\section{Thoracic Cirtometry}

Figure 2 shows the variation of thoracic amplitude in the Parkinson's, Alzheimer's, and control groups. According to 1-way analysis of variance, no difference was observed between the groups in relation to: (1) basal thoracic amplitude $(P=.32),(2)$ inspiratory thoracic amplitude $(P=.34)$, and (3) expiratory thoracic amplitude $(P=.37)$.

\section{Thoracic Cirtometry By Gender}

In relation to the cirtometric amplitude by gender, there was no difference between the men and women in the basal amplitude of the Parkinson's $(P=.47,95 \% \mathrm{CI}$ $=-3.76$ to 7.76$)$, Alzheimer's $(P=.10,95 \% \mathrm{CI}=-1.02$ to 9.48$)$, and control groups $(P=.10,95 \% \mathrm{CI}=-1.57$ to 16.10). Regarding analysis by gender involving maximum inspiratory amplitude, there was also no difference in the Parkinson's ( $P=.67,95 \% \mathrm{CI}=-2.80$ to 8.63), Alzheimer's $(P=.10,95 \% \mathrm{CI}=-1.01$ to 9.59$)$, and control groups $(P=.07,95 \% \mathrm{CI}=-0.56$ to 16.42$)$. The same result was obtained in the comparison by gender on the maximum expiratory amplitude in the Parkinson's $(P=.57$, $95 \% \mathrm{CI}=-4.17$ to 7.24$)$, Alzheimer's $(P=.09$, $95 \% \mathrm{CI}=-0.81$ to 9.94$)$, and control groups $(P=.90$, $95 \% \mathrm{CI}=-1.57$ to 20.03$)$.

\section{Discussion}

The aging process exercises a large influence on respiratory parameters. The increase in the abdominal cavity, the reduction in pulmonary elasticity, the rise in pulmonary vascular resistance, and the generalized muscular weakness are some factors involved in the pneumo-functional decline of the older adult. ${ }^{19}$ When associated with pathological processes, the changes are accentuated, and may compromise the subjects' routine activities.

We decided to use the manometer as an instrument for measuring maximum muscular strength for two reasons: first, it represents a highly sensitive method for cases of inspiratory muscular weakness $\left(\mathrm{P}_{\mathrm{Imax}}\right)$, and second, it reflects a parameter of the subjects' effectiveness of cough and expectoration $\left(\mathrm{P}_{\text {Emax }}\right){ }^{20}$ The results found in this study indicate that older adults with $\mathrm{PD}$ and $\mathrm{AD}$, even presenting anthropometric and cirtometric characteristics that are similar to those of healthy older adults, have greater compro- 


\section{Respiratory Strength in Parkinson's and Alzheimer's Disease}

Table 2. Mean and SD of the Values for Maximum Inspiratory Pressure and Maximum Expiratory Pressure by Gender

\begin{tabular}{|c|c|c|c|c|c|c|}
\hline & \multicolumn{2}{|c|}{ Parkinson's Group } & \multicolumn{2}{|c|}{ Alzheimer's Group } & \multicolumn{2}{|c|}{ Control Group } \\
\hline & Male & Female & Male & Female & Male & Female \\
\hline Age (y) & $71.7 \pm 8.8$ & $70.0 \pm 6.6$ & $77.6 \pm 5.6$ & $76.8 \pm 5.7$ & $69.8 \pm 10.6$ & $69.2 \pm 6.6$ \\
\hline Clinical profile & $2.5 \pm 0.5$ & $2.4 \pm 0.5$ & $2.6 \pm 0.5$ & $2.5 \pm 0.5$ & NA & NA \\
\hline $\mathrm{P}_{\operatorname{Imax}}$ & $-65.1 \pm 34.4$ & $-37.7 \pm 10.6$ & $-48.4 \pm 23.1$ & $-38.2 \pm 13.1$ & $-75.5 \pm 21.1$ & $-68.1 \pm 29.4$ \\
\hline $\mathrm{P}_{\text {Emax }}$ & $63.6 \pm 31.8$ & $36.7 \pm 11.3$ & $62.1 \pm 17.1$ & $43.9 \pm 18.6$ & $88.2 \pm 21.5$ & $75.0 \pm 19.1$ \\
\hline \multicolumn{7}{|c|}{$\begin{array}{l}\mathrm{NA}=\text { not applicable } \\
\mathrm{P}_{\text {Imax }}=\text { maximum inspiratory pressure } \\
\mathrm{P}_{\mathrm{Emax}}=\text { maximum expiratory pressure }\end{array}$} \\
\hline
\end{tabular}

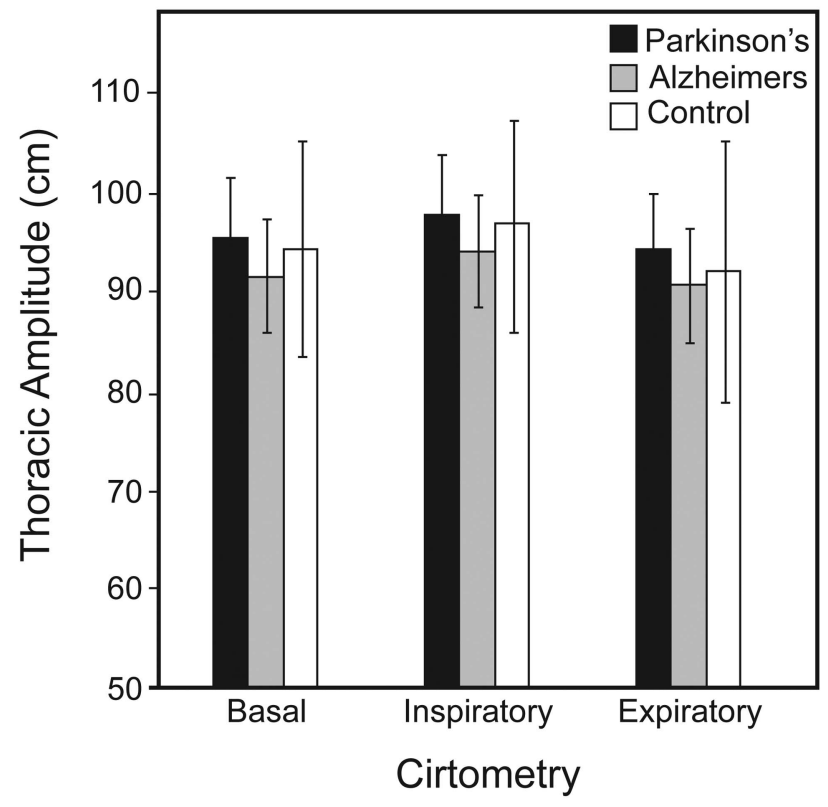

Fig. 2. Variation of cirtometric measurements for each group. Data are shown as mean \pm SD.

mise of maximum RMS (inspiratory and expiratory). In this case, understanding respiratory physiology and the influence of nosological conditions on this process is fundamental for reflection on the clinical findings.

Human respiration consists of an automatic body function, which depends on extrinsic motor command. The diaphragm, the principal human respiratory muscle, receives input from the phrenic motor neuron, originating from three main pathways: (1) the bulbo-spinal pathway, responsible for promoting the rhythmic respiratory pattern; (2) the cortico-bulbar-spinal pathway, which is involved, through its connection with the limbic system, in the modulation of respiration by emotion; and (3) the upper cortical pathways, which regulate respiration according to the synergic activation of other cerebral areas, such as speech or singing, for example. ${ }^{21,22}$ Thus, it is possible to assert that changes in one of these pathways may affect the efficacy of the muscle of the diaphragm.
The respiratory problems that older adults with PD present reflect the compromised values of $\mathrm{P}_{\mathrm{Imax}}$ and $\mathrm{P}_{\mathrm{Emax}}$, and result in situations of obstruction of the upper airways, restrictive disorders, and complications arising from aspiration. ${ }^{23}$ Mehanna and Jankovic ${ }^{24}$ hypothesized that the respiratory dysfunctions in PD may be the result of muscle dystonia causing abnormal rhythmic oscillations in the supraglottic structures. In addition to this, rigidity, freezing, and bradykinesia exacerbate the restrictive pulmonary dynamic, which, associated with the inefficacy of the cough reflex, predisposes the subject to an elevated risk of aspiration pneumonia. ${ }^{23,24}$

In spite of the most striking pathological modification in PD being the degeneration of the mesencephalic substantia nigra, recent studies prove that apoptotic processes suffered in the illness involve neuronal lesions adjacent to the basal nuclei that affect brainstem, locus coeruleus, and upper cerebral regions. ${ }^{25}$ Because of their compromised connective pathways, this study's clinical findings, which proved there were shortcomings in the patients' maximal respiratory strength $\left(\mathrm{P}_{\text {Imax }}\right.$ and $\left.\mathrm{P}_{\mathrm{Emax}}\right)$, are substantiated.

However, AD studies indicate respiratory complications as being a co-adjuvant outcome of the illness, affected above all by the patient's physical decline and total dependence in the final stage of the illness. Easterling and Robbins ${ }^{26}$ describe dysphagia and pulmonary aspiration as complications related to the process of human aging, and state that they are exacerbated in AD.

As the reduction in the sensitivity of the pharynx, the loss of dentition, the reduction in the capacity to produce saliva, and the slowing of the oral-pharyngeal reflex are signs common to old age, the structural alterations that occur in the brain of the patient with $\mathrm{AD}$ (with apoptosis and neuro-fibrillary tangles in cortical and sub-cortical regions) affect the efficacy of the pulmonary dynamic. In addition, the human cardiopulmonary capacity is directly influenced by the autonomic nervous system. In this context, Zakrzewska-Pniewska et $\mathrm{al}^{27}$ demonstrate that sympathetic and parasympathetic involvement occurs in $\mathrm{AD}$ in 
varying degrees, which may be related to the findings of $\mathrm{P}_{\text {Imax }}$ and $\mathrm{P}_{\text {Emax }}$ demonstrated in this study.

Studies have had difficulty predicting a reference value for $\mathrm{P}_{\text {Imax }}$ and $\mathrm{P}_{\mathrm{Emax}}$ in the Brazilian population. Although Neder et al, ${ }^{28}$ analyzing the same age range as the present study, found normality of $\mathrm{P}_{\text {Imax }}$ values of $-92.8 \pm 72.8 \mathrm{~cm}$ $\mathrm{H}_{2} \mathrm{O}$ for men and $-72.7 \pm 3.9 \mathrm{~cm} \mathrm{H}_{2} \mathrm{O}$ for women, Simões et $\mathrm{al}^{29}$ observed values of $-74.0 \pm 4.5 \mathrm{~cm} \mathrm{H}_{2} \mathrm{O}$ for men and $-57.6 \pm 5.1 \mathrm{~cm} \mathrm{H}_{2} \mathrm{O}$ for women. Regarding $\mathrm{P}_{\text {Emax }}$, there was also the same discrepancy of values: Neder et al ${ }^{28}$ found values of $111.5 \pm 21.0 \mathrm{~cm} \mathrm{H}_{2} \mathrm{O}$ for men and $69.6 \pm 6.7$ for women, and Simões et $\mathrm{al}^{29}$ observed values of $71.0 \pm 4.5 \mathrm{~cm} \mathrm{H}_{2} \mathrm{O}$ for men and $57.8 \pm 4.7 \mathrm{~cm} \mathrm{H}_{2} \mathrm{O}$ for the women. Despite use of the same methodology, the difference seen might be the result of differences in sample size. According to the values set up in the control group, the present study is closer to the reference values found by Simões et al. ${ }^{29}$

Because of the male biotype, it is common for the reference values for $\mathrm{P}_{\text {Imax }}$ and $\mathrm{P}_{\text {Emax }}$ to be slightly higher in men than in women, although this does not necessarily indicate a significant difference between the sexes. The present study corroborates this fact, apart from the values of the Parkinson's group, which were shown to be perceptibly lower in women compared with men. Regarding this, various convergent factors explain this finding, representing an important influence of women's anthropometric, clinical, and bioimpedance variables, in relation to men.

Excess weight and obesity are major clinical and public health problems worldwide. ${ }^{30}$ In our study, the average body mass index for participants puts them in the overweight category. Related to that, it is known that excess body fat influences lung function by mechanical and nonmechanical mechanisms; therefore, this could have affected the results. ${ }^{31}$ However, the homogeneity of the groups in this variable minimizes this bias by exercising a similar effect in each group.

Nonetheless, the mobility of the thoracic cage may represent one bias of the studies which address the subjects' pneumo-functional characteristics, as it exercises a direct influence on the patients' RMS. ${ }^{32}$ When we undertook the cirtometric evaluation of all subjects and observed statistical similarity between groups in the comparisons of the thoracic amplitude (normal respiration, maximum inspiration and expiration), we provided support to affirm that this factor does not exercise any influence on the subjects' $\mathrm{P}_{\text {Imax }}$ and $\mathrm{P}_{\text {Emax }}$ values. In addition to this, the exclusion of patients with possible alterations in the thoracic dynamic (commonly present in cases of barrel chest, pigeon chest, excavatum, carinatum, or kyphoscoliotic), made it possible for us to isolate this bias in the sample selection.

Furthermore, PD and AD are neurodegenerative conditions that cause a serious global decline in health for older adults, being commonly related to a high risk of falls and the subject's physical-functional dependence. ${ }^{33}$ Had the sample been heterogeneous in terms of the level of physical activity and the degree of functional independence, we would have been able to evaluate the influence of both processes on pneumo-functional values. ${ }^{34}$ Thus, we opted to restrict the sample to sedentary subjects who presented similar functional levels.

It is important to say that all subjects with $\mathrm{PD}$ and $\mathrm{AD}$ were evaluated while on their medications. We chose to maintain this delimitation, as previous studies show that medication based on dopamine (for PD) does not exercise any influence on the subjects' parameters of $\mathrm{P}_{\mathrm{Imax}}$ and $\mathrm{P}_{\text {Emax }}$, just like medication based on acetylcholinesterase inhibitors and N-methyl-D-aspartate antagonists (for $\mathrm{AD}$ ), which have a neuro-psycho-behavioral action..$^{23,35}$

\section{Limitations}

Although we believe this study does have merits, the limitations should be pointed out. One limitation is that we used cross-sectional data that do not allow us to assess causal relationships. Longitudinal research aimed at assessing the predictive value of pulmonary functions is needed to better understand the mechanisms whereby the central nervous system affects $\mathrm{P}_{\text {Imax }}$ and $\mathrm{P}_{\text {Emax }}$ in later years and to identify possible target areas for interventions.

Despite our having found differences between the subjects' ages, it is important to survey the mean age of the participants in this research. Benchmark studies previously published in the literature ${ }^{28,29}$ usually classify the subjects in age ranges of $10 \mathrm{y}$, indicating that possible differences in RMS from year to year are minimal. Thus, it is possible to assert that the age difference found in this study had little influence on the results.

Although one may argue about the small sample size, one has to consider the difficulty of recruiting subjects, as well as the fact of both pathologies presenting a complex diagnosis, requiring the integration of clinical evaluation with laboratory tests that are not always available. In AD, for example, the definitive diagnosis is undertaken by cerebral autopsy. In life, the use of structural neuroimaging exams (hippocampal volumetry, for example) and those of functional neuro-imaging (magnetic resonance spectrossist in making an accurate diagnosis. In PD, however, the difficulty in diagnosis is in differentiating idiopathic PD from Parkinsonian syndromes, which are secondary to cerebral compromise.

As our study involved the analysis of respiratory function, the use of another study center, with subjects living in another city, under another climate condition, air humidity, and pollution level could be a bias. Based on that, we restricted our sample to subjects living in Campo Grande, Mato Grosso do Sul, Brazil, a city located in the tropical 


\section{Respiratory Strength in Parkinson's and Alzheimer's Disease}

region, with $8,096 \mathrm{~km}^{2}$ of area, 113,862 hectares of natural reserve, and pollution level in agreement with that recommended by the World Health Organization. ${ }^{36}$

\section{Conclusions}

This study observed an important reduction in the maximum RMS in older adults with PD and AD, when compared with healthy control subjects. The groups' similarity in socio-demographic and cirtometric variables indicates that the $\mathrm{P}_{\operatorname{Imax}}$ and $\mathrm{P}_{\text {Emax }}$ values of the Parkinson's and Alzheimer's groups are more associated with the alterations arising from the clinical situations than from the aging process per se.

This fact represents a serious risk for developing atelectasis and other pneumo-functional complications, and must be considered in proposing future therapies. Additional studies should investigate a larger and more heterogeneous sample to ensure that the results are applicable to the general populations of $\mathrm{PD}$ and $\mathrm{AD}$ patients.

\section{ACKNOWLEDGMENTS}

We thank the National Council for Scientific and Technological Development $(\mathrm{CNPq})$ for technical and scientific support.

\section{REFERENCES}

1. Lalley PM. The aging respiratory system: pulmonary structure, function and neural control. Respir Physiol Neurobiol 2013;187(3):199210.

2. Simões LA, Dias JM, Marinho KC, Pinto CL, Britto RR. Relationship between functional capacity assessed by walking test and respiratory lower limb muscle function in community-dwelling elders. Rev Bras Fisioter 2010;14(1):24-30

3. Sharma G, Goodwin J. Effect of aging on respiratory system physiology and immunology. Clin Interv Aging 2006;1(3):253-260.

4. Singh-Manoux A, Dugravot A, Kauffmann F, Elbaz A, Ankri J, Nabi $\mathrm{H}$, et al. Association of lung function with physical, mental and cognitive function in early old age. Age 2011;33(3):385-392.

5. Vidal JS, Aspelund T, Jonsdottir MK, Jonsson PV, Harris TB, Lopez OL, et al. Pulmonary function impairment may be an early risk for late-life cognitive impairment. J Am Geriatr Soc 2013;61(1):79-83.

6. Reyes A, Ziman M, Nosaka K. Respiratory muscle training for respiratory deficits in neurodegenerative disorders: a systematic review. Chest 2013;143(5):1386-1394.

7. Dickson DW. Parkinson's disease and parkinsonism: neuropathology. Cold Spring Harb Perspect Med 2012;2(8). Doi:10.1101/cshperspect.a009258

8. Seccombe LM, Giddings HL, Rogers PG, Corbett AJ, Hayes MW, Peters MJ, et al. Abnormal ventilator control in Parkinson's disease: further evidence for non-motor dysfunction. Resp Physiol Neurobiol 2011;179(2-3):300-304.

9. Leung KK, Bartlett JW, Barnes J, Manning EN, Ourselin S, Fox NC, Alzheimer's Disease Neuroimaging Initiative. Cerebral atrophy in mild cognitive impairment and Alzheimer disease: rates and acceleration. Neurology 2013;80(7):648-654.

10. Danysz W, Parsons CG. Alzheimer's disease, $\beta$-amyloid, glutamate, NMDA receptors and memantine: searching for the connections. Br J Pharmacol 2012;167(2):342-352.
11. de Andrade LP, Gobbi LT, Coelho FG, Christofoletti G, Costa JL, Stella F. Benefits of mutimodal exercise intervention for postural control and frontal cognitive functions in individuals with Alzheimer's disease: a controlled trial. J Am Geriatr Soc 2013;61(11): 1919-1926.

12. Hughes AJ, Daniel SE, Kilford L, Lees AJ. Accuracy of clinical diagnosis of idiopathic Parkinson's disease: a clinicopathological study of 100 cases. J Neurol Neurosurg Psychiatry 1992;55(3):181184.

13. Hoehn MM, Yahr MD. Parkinsonism: onset, progression, and mortality. Neurology 1967;17(5):427-442.

14. McKhann G, Drachman D, Folstein M, Katzman R, Price D, Stadlan EM. Clinical diagnosis of Alzheimer's disease: report of this NINCDS-ADRDA work group under the auspices of Department of Health and Human Services Task Force on Alzheimer's disease. Neurology 1984;34(7):934-944.

15. Hughes CP, Berg L, Danziger WL, Coben LA, Martin RL. A new clinical scale for the staging of dementia. Br J Psychiatry 1982;140: 566-572.

16. Folstein MF, Folstein SE, Mchugh PR. Mini-mental state: a practical method for grading the cognitive state of patients for the clinician. J Psychiatr Res 1975;12(3):198-198.

17. Kakizaki F, Shibuya M, Yamazaki T, Yamada M, Suzuki H, Homma I. Preliminary report on the effects of respiratory muscle stretch gymnastics on chest wall mobility in patients with chronic obstructive pulmonary disease. Respir Care 1999;44(4):409-414.

18. Souza RB. Maximal static respiratory pressures. J. Pneumol 2002; 28(Suppl 3):S155-S165.

19. Taylor BJ, Johnson BD. The pulmonary circulation and exercise responses in the elderly. Semin Respir Crit Care Med 2010;31(5): 528-538.

20. Montemezzo D, Vieira DS, Tierra-Criollo CJ, Britto RR, Velosso M, Parreira VF. Influence of 4 interfaces in the assessment of maximal respiratory pressures. Respir Care 2012;57(3):392-398.

21. Laviolette L, Niérat MC, Hudson AL, Raux M, Allard E, Similowski T. The supplementary motor area exerts a tonic excitatory influence on corticospinal projections to phrenic motoneurons in awake humans. PLoS One 2013;8(4). doi: 10.1371/journal.pono.0062258.

22. Evans KC. Cortico-limbic circuitry and the airways: insights from functional neuroimaging of respiratory afferents and efferents. Biol Psychol 2010;84(1):13-25.

23. Guedes LU, Rodrigues JM, Fernandes AA, Cardoso FE, Parreira VF. Respiratory changes in Parkinson's disease may be unrelated to dopaminergic dysfunction. Arq Neuropsiq 2012;70(11):847-851.

24. Mehanna R, Jankovic J. Respiratory problems in neurologic movement disorders. Parkinsonism Relat Disord 2010;16(10):62838.

25. Hildebrandt H, Fink F, Kastrup A, Haupts M, Eling P. Cognitive profiles of patients with mild cognitive impairment or dementia in Alzheimer's or Parkinson's disease. Dement Geriatr Cogn Dis Extra 2013;3(1):102-112.

26. Easterling CS, Robbins E. Dementia and dysphagia. Geriatr Neurs 2008;29(4):275-285

27. Zakrzewska-Pniewska B, Gawel M, Szmidt-Salkowska E, Kepczynska K, Nojszewska M. Clinical and functional assessment of dysautonomia and its correlation in Alzheimer's disease. Am J, Alzheimers Dis Other Demen 2012;27(8):592-599.

28. Neder JA, Andreoni S, Lerario MC, Nery LE. Reference values for lung function tests. II. Maximal respiratory pressures and voluntary ventilation. Braz J Med Biol Res 1999;32(6):719-727.

29. Simões RP, Deus AP, Auad MA, Dionísio J, Mazzonetto M, BorghiSilva A. Maximal respiratory pressure in health 20 to 89 year-old sedentary individuals of central São Paulo State. Rev Bras Fisioter 2010; 14(1):60-7. 


\section{Respiratory Strength in Parkinson's and Alzheimer's Disease}

30. da Silva-Hamu TC, Formiga CK, Gervásio FM, Riveiro DM, Christofoletti G, de França Barros J. The impact of obesity in the kinematic parameters of gait in young women. Int J Gen Med 2013;24:6:507-513.

31. Steele RM, Finucane FM, Griffin SJ, Wareham NJ, Ekelund U. Obesity is associated with altered lung function independently of physical activity and fitness. Obesity (Silver Spring) 2009;17(3):578-584.

32. Lanza FD, de Camargo AA, Archija LR, Selman JP, Malaguti C, Dal Corso $\mathrm{S}$. Chest wall mobility is related to respiratory muscle strength and lung volumes in healthy subjects. Respir Care 2013;58(12): 2107-2112.

33. Christofoletti G, Oliani MM, Gobbi LTB, Gobbi S, Stella F. Risco de quedas em idosos com doença de Parkinson e demência de Alz- heimer: um estudo transversal. Rev Bras Fisioter 2006;10(4):429433.

34. Ciolac EG. Exercise training as preventive tool for age-related disorders: a brief review. Clinics 2013;68(5):710-717.

35. Kano O, Ito H, Takazawa T, Kawase Y, Murata K, Iwamoto K et al. Clinically meaningful treatment responses after switching to galantamine and with addition of memantine in patients with Alzheimer's disease receiving donepezil. Neuropsychiatr Dis Treat 2013;9259-9265.

36. Coleti RCFB, Luchmann R, Dambrós SR. Relatório de avaliação ambiental: programa de desenvolvimento integrado e qualificação urbana do município de Campo Grande MS. Campo Grande, Brazil: Prefeitura Municipal de Campo Grande; 2007.

This article is approved for Continuing Respiratory Care Education credit. For information and to obtain your CRCE

(free to AARC members) visit www.rcjournal.com 